\title{
Gender differences in activity patterns of American mink Neovison vison in Germany
}

\author{
Jana Zschille • Norman Stier • Mechthild Roth
}

Received: 27 February 2009 /Revised: 7 July 2009 /Accepted: 9 July 2009 /Published online: 24 July 2009

(C) Springer-Verlag 2009

\begin{abstract}
Circannual and circadian activity patterns of American mink Neovison vison were studied in a fishpond area in northern Germany. Fourteen mink were radiotracked, nine of them (five males, four females) for at least 6 months, some of them even up to 21 months. Both sexes have reduced activity rates in winter months and showed a considerable increase of activity during mating season (March). In summer months - during the pup raising period-female activity continued to be high. Male mink, on the other hand, were less active with the exception of August and September. During this time, dispersal of juveniles takes place with resident males increasingly having to defend their territories. Circadian activity rhythms differed markedly between sexes. All investigated females exhibited a perennial diurnal pattern. Female activity during twilight and night was significantly lower than during daylight. Three investigated male mink showed a typical nocturnal course throughout the year. Daylight activity of these animals was very low, increased during dusk and dawn activity rates and stayed at a higher level during the night. Two males behaved arrhythmic; they did not prefer any time of the day for activity. The observed temporal strategies were discussed in context of intra-sexual territoriality, sexual dimorphism in body size and different environmental factors.
\end{abstract}

Keywords Mustela vison - Activity rhythms . Inter-sexual competition · Diurnal behaviour · Telemetry

Communicated by W. Lutz

J. Zschille $(\bowtie) \cdot$ N. Stier $\cdot$ M. Roth

Institute of Forest Botany and Forest Zoology,

Dresden University of Technology,

Pienner Str. 7,

01737 Tharandt, Germany

e-mail: zschille@forst.tu-dresden.de

\section{Introduction}

Seasonal as well as circadian activity rhythms of mammalian carnivores are influenced by diverse environmental factors, including food availability, risk of predation and human hunting, reproduction and interference from competitors as well as temperature variation (Halle and Stenseth 2000). Whereas the endogenous circadian rhythm is overlaid by the behavioural response to the exogenous environmental events, activity generally occurs within a circadian threshold, which is governed by light-dark cycle (Daan and Aschoff 1982).

Apart from arrhythmic or polycyclic species, there are three alternative circadian basic patterns: nocturnal, diurnal and crepuscular. For small mustelids, the most common activity time appears to be during the night, followed by crepuscular activity, whereas diurnal activity is much less common (Halle and Stenseth 2000).

Both seasonal and circadian cycles of prey vulnerability were often used as an explanation for the activity rhythms of predators. Many studies on mustelids focussed on this predator-prey synchronisation (Gerell 1969; Zielinski 1988; Lodé 1995), but daily activity patterns may result from a complex trade-off between different environmental factors, physiological constraints and energy requirements (Marcelli et al. 2003).

The American mink Neovison vison is a semi-aquatic medium-sized mustelid with a distinct sexual dimorphism in body size, which is related to different reproductive strategies of sexes in the context of a polygynous mating system with lack of male parental care (Wiig 1982). Intra-sexual territoriality with extensive home range overlap between sexes is the typical spacing pattern in mink as in many other mustelids (Dunstone 1993; Powell 1994). This territorial system may cause resource competition between sexes. Sexual dimorphism and inter-sexual competition may result in divergent behaviour and ecology including different temporal strategies. 
Until now, few studies have focussed on the activity behaviour of the American mink. Most of them obtain data through the continuous tracking method (Gerell 1969; Birks and Linn 1982; Niemimaa 1995; Harrington and Macdonald 2008). This method causes short observation periods for a few weeks, which is why seasonal changes in activity rhythms could not be recorded. Some authors analysed few locations, so their results are questionable (Zuberogoitia et al. 2006).

In this paper, circannual and circadian activity patterns of American mink monitored in the field using radiotelemetry techniques were analysed. This study aims at following points: (1) variation in monthly activity rates of females and males in relation to seasons and reproductive status and (2) circadian activity patterns of both sexes during different seasons in relation to prey availability, temperature, predator avoidance and intra-specific competition.

\section{Study area}

Our study was conducted in an about $120-\mathrm{km}^{2}$-wide lowland ('Lewitz') located approximately $20 \mathrm{~km}$ southeast of the city of Schwerin (Mecklenburg-Western Pomerania,

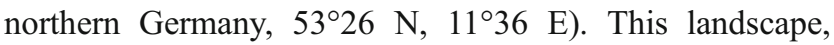
considerably shaped by man, is characterised by forests, meadows, pastures and wooded inland dunes, scattered along the meandering River Alte Elde, a tributary of the River Elbe. The 'Lewitz' area is protected as a Ramsar Site and a European Bird Reserve with Special Protection Area legislation (Zimmermann 2002). Some large carp ponds cover a region of almost $10 \mathrm{~km}^{2}$. They make up the main part of our study area, because most of radiotracked mink used this habitat. The fishponds are a nature reserve with seasonal changes in water level. In winter, most of them are completely drained off. Reed belts (Phragmitetum) characterise the eutrophic ponds, with willows (Salix sp.), birches (Betula pendula) and poplars (Populus sp.) skirting the river banks and lake edges (Möller 2002).

The climate is relatively mild and humid. For the last 30 years, the average annual precipitation was $646 \mathrm{~mm}$ and average annual temperature was $8.4^{\circ} \mathrm{C}$ with $-0.4^{\circ} \mathrm{C}$ in January and $16.8^{\circ} \mathrm{C}$ in July (meteorological station Schwerin, http://www.dwd.de).

\section{Materials and methods}

Between October 2003 and June 2005, altogether 16 mink were caught in baited cage traps of various sizes (minimum size $=20 \times 20 \times 70 \mathrm{~cm}$ ) which were made of wire mesh or wood. We recorded gender, age class, weight and morphological parameters. Each mink was individually marked with a subcutaneous transponder (Trovan ${ }^{\circledR}$ ).

Animals captured between October 2003 and March 2004 were fitted with waterproof transmitter collars (Wagener-Telemetrysystems, Köln, Germany). After the discovery of injuries in March 2004, all collars were removed and we switched to intra-peritoneal transmitters (Wagener-Telemetrysystems, Köln, Germany and Biotrack Ltd., Wareham, Dorset, UK). For fate of studied animals, anaesthetic, surgical procedure and further method information, see Zschille et al. (2008).

Between October 2003 and April 2006, 14 mink (nine males and five females) were radiotracked for various tracking periods (Table 1). Animals were searched for by car and precisely located on foot, using triangulation and

Table 1 Sex, number of locations and tracking periods of radiotracked American mink

\begin{tabular}{|c|c|c|c|c|}
\hline \multirow{2}{*}{$\begin{array}{l}\text { Animal ID } \\
\text { F2 }\end{array}$} & \multirow{2}{*}{$\frac{\text { Sex }}{q}$} & \multirow{2}{*}{$\begin{array}{c}\text { Locations } \\
676\end{array}$} & \multicolumn{2}{|l|}{ Tracking periods } \\
\hline & & & 16 October 2003-29 October 2004/6 December 2004-7 February 2005 & 14.5 months \\
\hline F3 & q & 464 & 26 November 2003-14 September 2004 & 9.5 months \\
\hline F6 & q & 383 & 5 February 2004-27 September 2004 & 8.0 months \\
\hline F9 & q & 204 & 29 July 2004-10 January 2005/24 February 2005-9 March 2005 & 6.0 months \\
\hline F10 & q & 65 & 10 August 2004-27 September 2004 & 1.5 months \\
\hline M1 & $\hat{\sigma}$ & 66 & 14 October 2003-18 November 2003 & 1.0 months \\
\hline M4 & $\hat{0}$ & 923 & 27 November 2003-2 March 2004/30 March 2004-20 September 2005 & 21.0 months \\
\hline M5 & $\hat{0}$ & 234 & 28 November 2003-24 February 2004/30 March 2004-2 July 2004 & 6.0 months \\
\hline M7 & 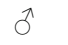 & 55 & 11 February 2004-4 March 2004 & 3.0 weeks \\
\hline M8 & 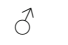 & 452 & 31 March 2004-14 May 2005 & 13.5 months \\
\hline M11 & 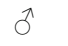 & 73 & 12 August 2004-10 September 2004/25 October 2004-14 November 2004 & 1.5 months \\
\hline M12 & $\hat{\jmath}$ & 39 & 24 October 2004-22 November 2004 & 1.0 month \\
\hline M15 & $0^{\lambda}$ & 419 & 27 February 2005-08 October 2005 & 7.5 months \\
\hline M16 & $\hat{\sigma}$ & 326 & 10 March 2005-18 April 2005/4 June 2005-2 May 2006 & 12.0 months \\
\hline
\end{tabular}


homing (Kenward 2001). Individuals were classified as inactive or active based on change in signal strength (no change for at least $60 \mathrm{~s}=$ inactive). To exclude impact on activity pattern of animals by researcher, this classification was made in a distance of about $50 \mathrm{~m}$. For exact locations, the average tracking distance was about $10 \mathrm{~m}$. For monitoring, we used a portable ${ }^{\circledR}$ TRX-1000S receiver (Wildlife Materials Inc., Murphysboro, IL, USA) connected to an H-antenna (HB9CV).

To keep data homogeneity, we aspired to sample the locations uniformly over a 24 -h period on a monthly basis. In order to minimise auto-correlation, only records separated by at least $1 \mathrm{~h}$ were used for analyses (Rooney et al. 1998).

Two biological periods were defined: 'summer' from March to September and 'winter' from October to February inclusive. Therefore, the summer period included the mating season, the birth and rearing of young and the migration of juveniles.

\section{Data analyses}

\section{Circannual activity pattern among sexes}

Circannual activity patterns were analysed with records of all radiotracked mink (Table 1). We created sex-specific activity patterns by pooling data of all females and all males, respectively. To minimise imbalances due to different portions of day and night activity of the individuals, the 24-h cycle was divided in eight 3-h periods. For each 3-h period, proportions of active records were assessed and averaged on a monthly basis.

Mean activity rates per season and sex were calculated. Variation in seasonal activity rates of females and males was tested with Mann-Whitney $U$ test. This test was also used to compare activity rates of both sexes within each season.

\section{Circadian activity pattern among sexes and seasons}

For these analyses, data of nine mink (five males and four females), whose tracking period was at least 6 months, were used (Table 1). Circadian activity patterns were estimated by calculating the individual proportions of active records during 12 2-h periods and during three light phases: daylight, night and twilight (including dusk and dawn). To account for photoperiodism, we used the online 'sunrise and sunset calculator' (http://sonne.apper.de) for dividing our data into the three periods.

In order to compare circadian activity patterns among individuals, Spearman's coefficient of rank correlation was used. Similar patterns were indicated by positive significant correlations. Additionally, absolute activity frequencies were calculated and compared by the chi-square $\left(\chi^{2}\right)$ test.
We tested differences in daylight, night and twilight activity among all individuals. The results allowed us to pool data of individuals with similar circadian activity patterns. A Friedman's test was carried out to find significant preferences of activity between the three different light phases. For all statistical analyses, SPSS 12.0 was used.

\section{Results}

We used 4,379 radiolocations for analysing activity patterns. On average $45 \pm 10$ (standard deviation, SD) records per month for each animal were obtained.

\section{Circannual activity pattern among sexes}

In winter months (October to February), both sexes showed a similar low level of activity but there was a significant higher activity rate in summer (March to September; Mann-Whitney $U$ test: males $Z=2.6795, N=12, p=0.004$ and females $Z=-2.8419, N=12, p=0.002)$. On average, female mink were active during $41.4 \pm 5.5 \%( \pm \mathrm{SD})$ of the 24-h period in summer, whereas the winter activity rate of $22.6 \pm 3.8 \%$ ( $\pm \mathrm{SD})$ was almost half as much. Males had an average activity rate of $34.1 \pm 7.6 \%( \pm \mathrm{SD})$ in summer and $23.2 \pm 1.8 \%( \pm \mathrm{SD})$ in winter. An increase of activity in March was recorded, where females and males were active during $38.9 \%$ and $38.3 \%$, respectively, of the $24-\mathrm{h}$ period. From April to July, male mink were less active than female mink, but during August and September, male activity rate increased again, reaching $43.3 \%$. In October, both sexes reduced their daily activity to the low winter level (Fig. 1). During the summer season, activity rates of females were significantly higher than those of males (Mann-Whitney $U$ test: $Z=-1.8527, N=14, p=0.032$ ), whereas in winter, there were no significant differences.

\section{Circadian activity pattern among sexes and seasons}

All four females showed a similar diurnal course (Spearman's coefficient of rank correlation: $r_{\mathrm{S}}=0.53$ to $0.82 ; p=$ 0.05 ). The individual circadian activity of three males (M4, M5, M16) were also similar (Spearman's coefficient of rank correlation: $r_{\mathrm{S}}=0.44$ to $0.70 ; p=0.075$ ), with a nocturnal pattern. The activity of two (M8, M15) of the five analysed males was arrhythmic and did not fit any other observed mink activity (Spearman's coefficient of rank correlation: $r_{\mathrm{S}}=-0.007$ to -0.23 , not significant). These three groups of individuals differed significantly in the distribution of activity rates among light phases $\left(\chi^{2}=45.39, d f=4, p<\right.$ $0.0001)$. The results of bivariate correlation and chi-square test allow us to create two patterns by pooling data from all females and from the three nocturnal males. 
Fig. 1 Circannual activity pattern of female $(N=5)$ and male $(N=9)$ American mink. Data are mean proportions of active fixes of eight 3 -h periods of the 24-h cycle

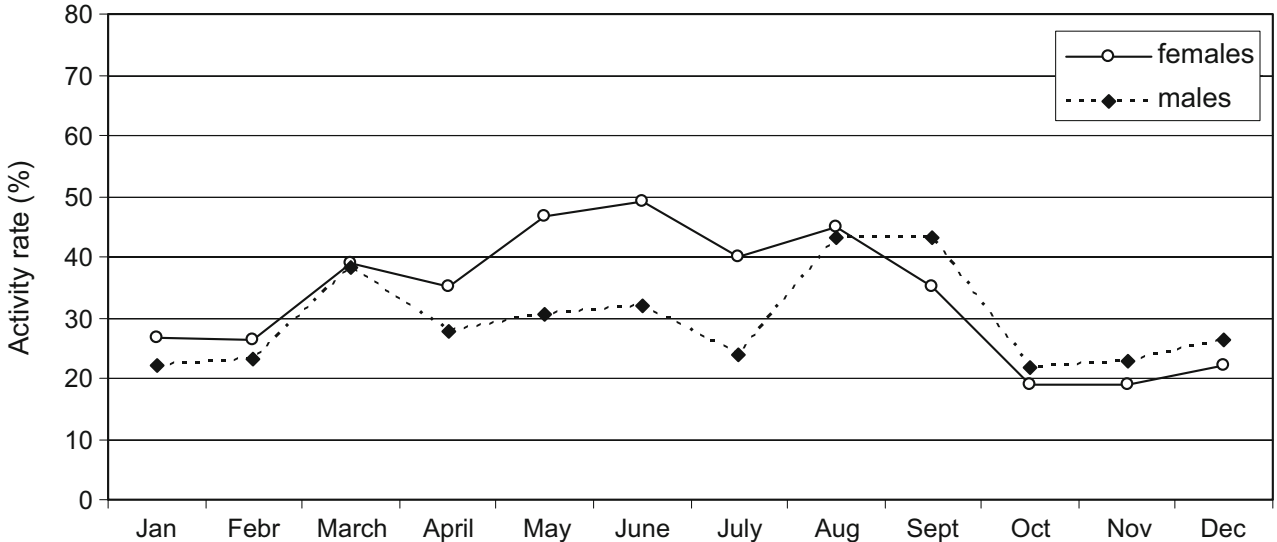

\section{Male mink}

Three of five studied males (M4, M5, M16) showed a typical nocturnal activity course in summer. Around sunrise, the rate of activity decreased and was maintained at a low level of about $20 \%$ with a slightly higher rate of $30 \%$ during the afternoon, whereas around sunset, the activity rate increased up to almost $60 \%$ (Fig. 2). The activity course for winter was similar in the longer night period between 1800 and 0800 hours, activity increased and reached a peak of around $40 \%$ in the early morning (Fig. 2). Median of activity rates $( \pm \mathrm{SD}$ ) in summer was $46.5 \pm 9.4 \%$ at night and $46.2 \pm 8.4 \%$ at twilight, whereas it was only $24.4 \pm 3.1 \%$ at daylight (Fig. 5). Also in winter, a nocturnal trend was recorded; however, for both seasons, the differences of activity between light periods were not significant (Friedman test: $\chi^{2}=4.667, d f=2, p=0.097$ ).

The two other males (M8, M15) showed arrhythmic or irregular activity patterns (Fig. 3). We observed no differences among night, twilight and daytime activity rates. The portion of activity in the three different light phases varied between $14 \%$ and $19 \%$ (median) in winter and from $27 \%$ to $33 \%$ (median) in the summer period. However, both males tend to be more nocturnal in the mating season (March).
Female mink

Calculating overall activity rates of three light phases show that in both seasons, females significantly prefer daylight (Friedman test: $\chi^{2}=6.00, d f=2, p=0.050$ for winter; $\chi^{2}=$ 6.50, $d f=2, p=0.039$ for summer). At sunrise, activity percentages considerably increased reaching a peak of $63 \%$ at midday in summer and $45 \%$ in winter. At sunset, the activity rates dropped off to approximately $20 \%$ in summer and $5-20 \%$ in winter (Fig. 4). At daylight, the median ( \pm $\mathrm{SD})$ is $39.6 \pm 4.2 \%$ in winter and $53.6 \pm 8.6 \%$ in summer, while twilight and night activity rates were considerably lower (Fig. 5). However, during summer, when total female activity rates increased, we recorded a certain level of twilight and night activity too.

\section{Discussion}

Circannual activity pattern among sexes

Mink and other mustelids are known to reduce their external activity during cold weather (Birks and Linn 1982; Skirnisson 1986; Robitaille and Baron 1987; Buskirk
Fig. 2 Circadian activity pattern of three nocturnal male mink (M4, M5, M16). Data are mean proportion of active fixes during each time period

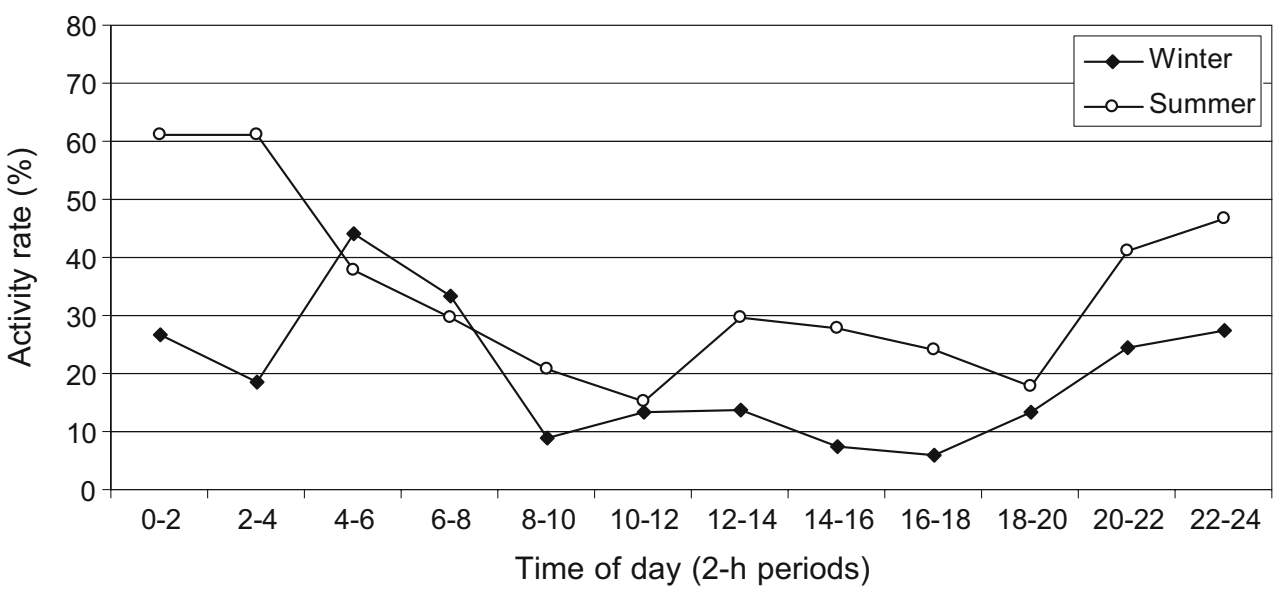


Fig. 3 Circadian activity pattern of two indifferent male mink (M8, M15). Data are mean proportion of active fixes during each time period

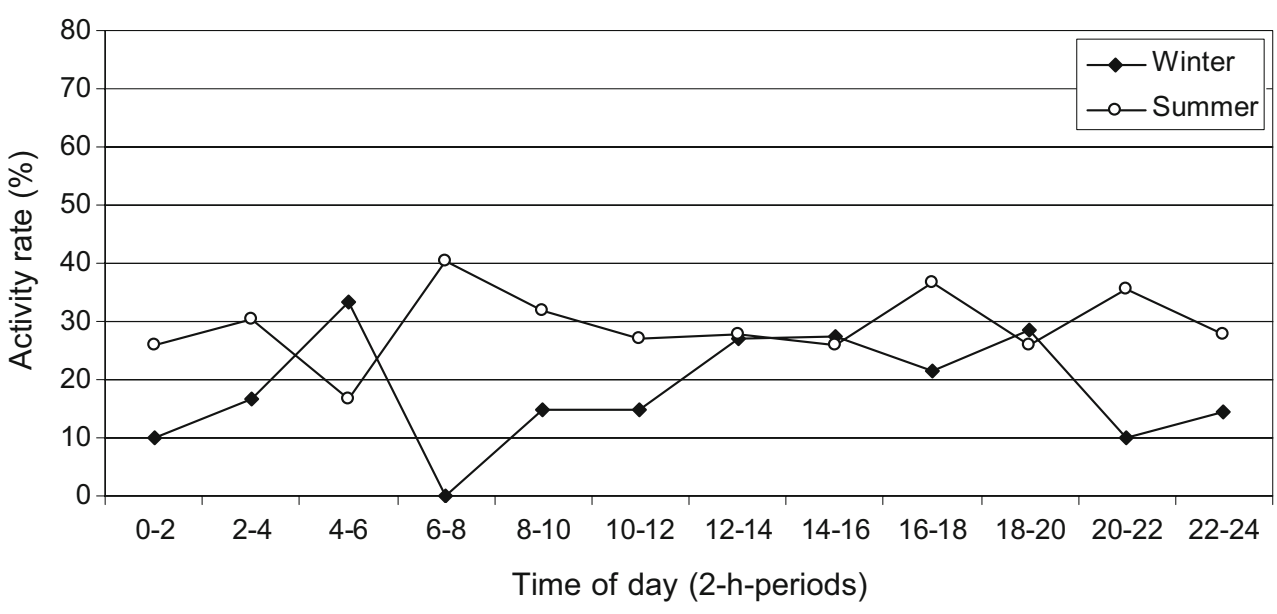

et al. 1988; Dunstone 1993; Niemimaa 1995). For some mustelids, activity can increase energy consumption by up to six times the basal metabolic rate (Powell 1979). That is why animals restrict their activities to hunting and minimise territorial behaviour in winter month to save energy. This energy-saving strategy is possible if there is a sufficient food supply. In our study area, mink mainly rely on fish in winter months (Zschille 2006). This is the time when the large fishponds are drained, but in canals and small ditches, there remains a sufficient supply of fish (Wichmann 2002).

As we observed, male's home ranges became much larger during the mating season as they searched for receptive females. They often met adjacent territorial or transient males, which can lead to aggressive confrontations (Zschille 2006). This behaviour caused the recorded increasing activity rates. Females were more sedentary than males at this time, but they also exhibited greater levels of activity than in the months before. This is probably caused by hormonal modifications and frequent meetings with males. Some other studies have shown that resident male American mink abandon their home ranges and start to roam during the breeding season; females, however, tend to stay in their home ranges throughout the year (Dunstone and Birks 1983; Ireland 1990; Yamaguchi et al. 2003). Correspondingly, Arnold and Fritzell (1987) as well as Ireland (1990) found activity peaks of male mink during the mating season. Furthermore, male European mink Mustela lutreola and polecats Mustela putorius also show longer activity periods and higher mobility during this time (Lodé 1999; Garin et al. 2002).

The decrease of female activity in April can be attributed to pregnancy and the birth of the young. Two out of the three females radiotracked at this time gave birth to their young in the last days of April. Gerell (1969) also reported a low activity level of pregnant females. Usually, pregnancy leads to higher levels of energy consumption. However, feeding trials with farm mink showed that only $6 \%$ more food is required during gestation (Dunstone 1993).

From May to August, high activity rates of investigated females were recorded. The feeding requirements of lactating mink increase considerably at this time (Gerell 1969; Ireland 1990). In the month after weaning, the females are kept busy carrying prey to their young; this requires an increased foraging effort resulting in higher activity again. Additionally, in late May until late June, both rearing females were observed individually moving
Fig. 4 Circadian activity pattern of four diurnal female mink (F2, F3, F6, F9). Data are mean proportion of active fixes during each time period

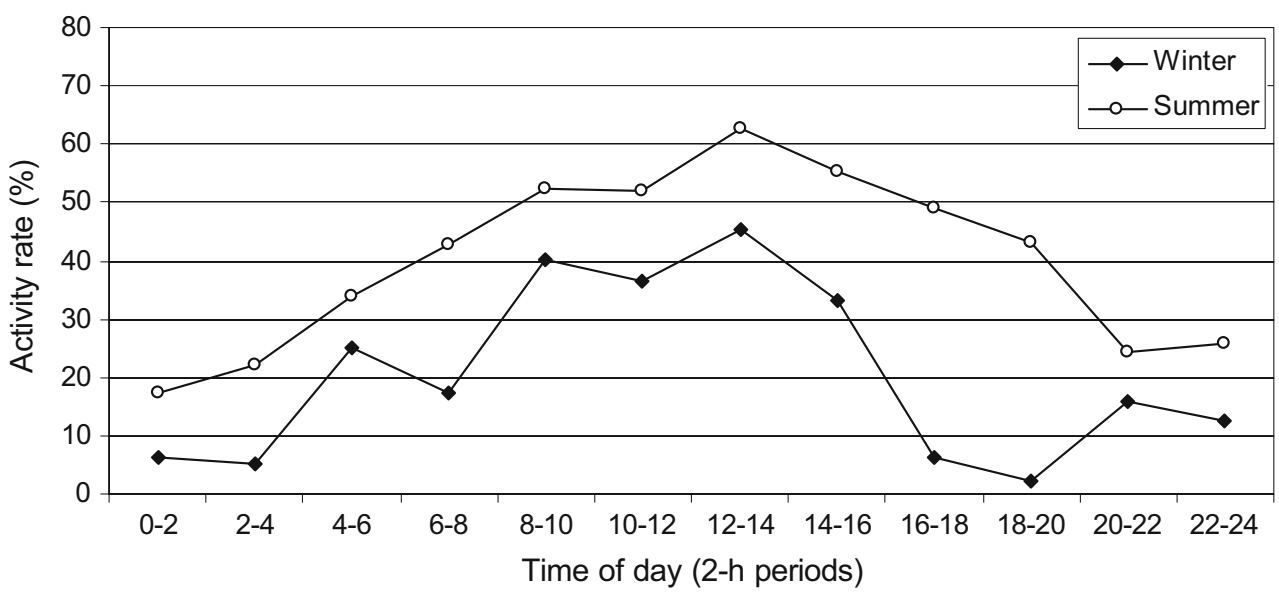


Fig. 5 Overall activity rates of diurnal female mink F2, F3, F6, F9 (a) and nocturnal male mink M4, M5, M16 (b) in the different light phases. Box and whisker plots show median (horizontal line within box), $25 \%$ and $75 \%$ percentiles (box) and range (plus sign)
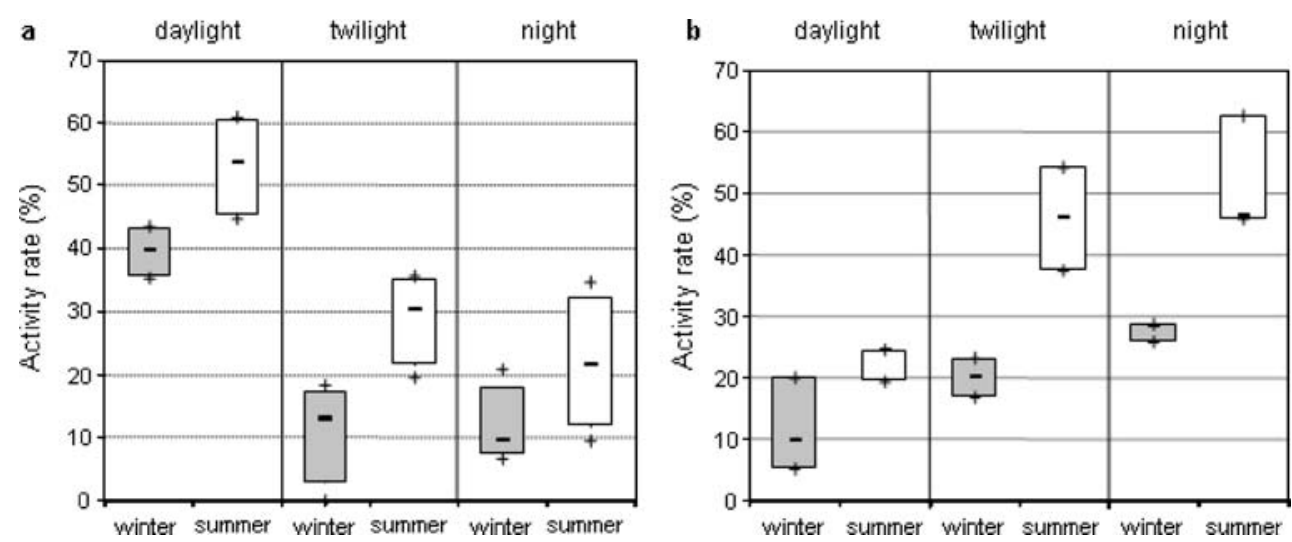

their young to other dens three times. This behaviour was also noted by Gerell (1969), who suggested an accumulation of waste in the dens. In the middle of August, the juveniles usually become independent from their mothers and the activity rates of females decreased during September to reach the low winter level in October. The higher energy requirements during the rearing period may explain significant differences of activity rates between the sexes in the summer months.

During August and September, the dispersal of juveniles starts (Dunstone 1993). This can lead to conflicts between resident territorial animals and transient individuals. Resident males are probably forced to defend their territories more often at this time. This behaviour may explain the observed high activity rates of male mink.

\section{Circadian activity pattern among sexes and seasons}

The activity behaviour of three of our five analysed male mink with high levels during the night, less during twilight and lowest during the day appears to be the most common activity behaviour for small mustelids (Halle and Stenseth 2000). Some studies of American mink, polecat and European mink actually found prevailing nocturnal activity patterns for both sexes (Gerell 1969; Melquist et al. 1981; Lodé 1995; Garin et al. 2002). Irregular temporal strategies with activity equally distributed during daylight and darkness, as we have recorded for two males, have also been observed in other studies on mink and polecat. This activity could possibly be due to the availability of food resources or avoidance of intra-specific competition (Gerell 1969; Birks and Linn 1982; Niemimaa 1995; Marcelli et al. 2003).

However, according to our results, other studies also recorded diurnal female mink (Dunstone 1993; Niemimaa 1995; Zuberogoitia et al. 2006) as well as diurnal female polecats (Marcelli et al. 2003). There have been different attempts to explain these sexually diverse temporal strategies. The main involved factors are prey availability (e.g.
Dunstone 1993; Lodé 1995), air temperature (e.g. Chappell 1980; Zalewski 2001), predator avoidance (e.g. Zuberogoitia et al. 2006) and intra-specific competition (e.g. Birks and Linn 1982; Marcelli et al. 2003; Thom et al. 2004).

\section{Prey availability}

In theory, predators will synchronise their activity with that time of day, when their prey is most vulnerable (Halle and Stenseth 2000). The variable and complex activity patterns of mink often were explained with different major prey groups. Small mammals are predominantly active at night or twilight and therefore most vulnerable at this time; waterfowl are mainly diurnal but easier to catch at night. Aquatic prey, on the other hand, may be more accessible in daylight because of the limited visual capability of mink under water (Dunstone 1993). Arnold and Fritzell (1987) found daytime activity more prevalent in areas with a high proportion of fish in the mink's diet. Dunstone (1993) explains the diurnality of female mink with short food passage time in connection with smaller prey. This can require the animal to hunt more frequently also in daylight. Analysis of more than 2,500 scats of our radiotracked mink showed that there is no sexual segregation in the use of prey (Zschille, unpublished). In spite of different seasonal diets, the observed circadian activity patterns were equal throughout the year. That is why prey availability does not seem to be the main factor of influence, which could explain different temporal strategies of the sexes.

\section{Temperature}

The higher surface-to-volume ratio of smaller female mustelids causes a higher energy loss as a result of increased thermal conductance compared to males (Harlow 1994). With diurnality, females are able to avoid activity during cold winter nights which gives energy-saving benefits in relation to thermoregulation. In Białowieża National Park, Zalewski (2001) observed that in winter, 
female European pine martens Martes martes decreased their activity rates during the colder periods of the night. Chappell (1980) found that most arctic mammals, including the least weasel Mustela nivalis, could save about $30 \%$ of thermoregulatory costs if they were diurnal in winter. Consequently, daily temperature variation possibly affects the daytime activities of our investigated smaller female mink especially in the winter season.

\section{Predator avoidance}

The risk of predation can greatly influence activity behaviour (Halle and Stenseth 2000). Daytime activity of studied female mink could be a way to avoid nocturnal predators such as European otter Lutra lutra, red fox Vulpes vulpes and racoon dog Nyctereutes procyonoides, which are common in our study area. Additionally, the influence of human hunting and disturbance is very low especially at night. The risk of predation is higher for smaller females and juveniles than for males. However, in other study areas, diurnal activity can also increase the risk of predation because of the large number of daytime predators like dogs, cats and diurnal birds of prey (Zuberogoitia et al. 2006). Such risks can be reduced by exploiting sheltered river banks covered by dense vegetation and moving quickly across open areas, as we have observed during radiotracking.

\section{Intra-specific competition}

Intra-sexual territoriality of most mustelids, implying considerable overlap of male and female home ranges, leads to the necessity of resource partitioning between individuals of different sexes. Several mechanisms have been noted that appear to reduce inter-sexual competition, e.g. spatial segregation between sexes (Lodé 1996; Yamaguchi et al. 2003; Zabala et al. 2007). A number of studies have shown that there are sexual differences between prey groups and prey size in connection with the dimorphism in body size (Birks and Dunstone 1985; Thom et al. 2004). Finally, gender-dependent activity pattern has also been proposed as a mechanism to reduce inter-sexual competition (Birks and Linn 1982; Marcelli et al. 2003; Thom et al. 2004).

We found no food niche partitioning between the studied male and female mink, and additionally, there was no sexual segregation in range use (Zschille, unpublished). Taking into account all of these facts, our suggested explanation for daytime activity of the studied female mink is temporal resource partitioning to minimise inter-sexual competition. Circadian time segregation between sexes allows females to enter a patch to a different time than males. This will increase their hunting successes if it is assumed that prey remains depressed for a short time after a male has visited the area. Additionally, outside the mating season, females may try to avoid costly encounters with larger and more dominant males as reported by Moors (1980). Gender differences in circannual as well as circadian activity patterns of American mink reflects the diversity in ecological constraints and in reproduction investment, while different temporal strategies may have the potential to reduce intra-specific and inter-sexual competition.

Acknowledgements This research was funded by the Ministry of Agriculture and Forestry and the Hunting Association MecklenburgWestern Pomerania (VI $220 \mathrm{c}$ ), as well as by a fellowship of the Saxonian State Ministry for Science and the Fine Arts (522-med). We thank Dr. Römisch and Prof. Berger for their statistical advice as well as Julia Müller and Trevor Banham for their helpful linguistic comments on the manuscript. The investigation was permitted by the State Authority for Veterinary Mecklenburg-Western Pomerania (file number: LVL M-V/TSD/7221.3-1.1-010/04). The experiments comply with the current laws of Germany. The authors declare that they have no conflict of interest.

\section{References}

Arnold TW, Fritzell EK (1987) Activity patterns, movements and home ranges of prairie mink. Prairie Nat 19(1):25-32

Birks JDS, Dunstone N (1985) Sex-related differences in the diet of mink (Mustela vison). Holarct Ecol 8:45-52

Birks JDS, Linn IJ (1982) Studies on the home range of feral mink (Mustela vison). Symp Zool Soc Lond 49:231-257

Buskirk SW, Harlow HJ, Forrest SD (1988) Temperature regulation in American marten in winter. Natl Geogr Res 4:208-218

Chappell MA (1980) Thermal energetics and thermoregulatory costs of small arctic mammals. J Mammal 61:278-291

Daan S, Aschoff J (1982) Circadian contributions to survival. In: Aschoff J, Daan S, Groos GA (eds) Vertebrate circadian systems: structure and physiology. Springer, Berlin, pp 305-321

Dunstone N (1993) The mink. Poyser Natural History, London

Dunstone N, Birks JDS (1983) Activity budget and habitat usage by coast-living mink (Mustela vison). Acta Zool Fenn 174:189-191

Garin I, Aihartza J, Zuberogoitia I, Zabala J (2002) Activity pattern of European mink (Mustela lutreola) in southwestern Europe. Z Jagdwiss 48:102-106

Gerell R (1969) Activity patterns of the mink Mustela vison Schreber in southern Sweden. Oikos 20:451-460

Halle S, Stenseth NC (2000) Activity patterns in small mammals - an ecological approach. Springer, Berlin

Harlow HJ (1994) Trade-offs associated with the size and shape of American marten. In: Buskirk SW, Harested AS, Raphael MG, Powell RA (eds) Martens, sables and fishers, biology and conservation. Cornell University Press, London, pp 391-403

Harrington LA, Macdonald DW (2008) Spatial and temporal relationships between invasive American mink and native European polecats in the southern United Kingdom. J Mammal 89(4):9911000

Ireland MC (1990) The behaviour and ecology of the American mink (Mustela vison Schreber) in a coastal habitat. Ph.D. thesis, Durham University, Durham, UK

Kenward ER (2001) A manual for wildlife radio tagging. Academic, London 
Lodé T (1995) Activity pattern of polecats Mustela putorius in relation to food habits and prey activity. Ethology 100:295-308

Lodé T (1996) Conspecific tolerance and sexual segregation in the use of space and habitats in the European polecat. Acta Theriol 41:171-176

Lodé T (1999) Time budget as related to feeding tactics of European polecat Mustela putorius. Behav Processes 47:11-18

Marcelli M, Fusillo R, Boitani L (2003) Sexual segregation in the activity patterns of European polecats (Mustela putorius). J Zool 261:249-255

Melquist WE, Whitman JS, Hornocker MG (1981) Resource partitioning and co-existence of sympatric mink and river otter populations. In: Chapman JA, Pursley P (eds) Proceedings of the worldwide furbearer conference, vol. 1. Frostburg, Maryland, USA

Möller C (2002) Über die Pflanzenwelt. In: NABU MecklenburgVorpommern (ed) Die Lewitz-Ein Lebensraum im Wandel der Zeit. Schwerin, pp 33-37

Moors PJ (1980) Sexual dimorphism in the body size of mustelids (Carnivora): the roles of food habits and breeding system. Oikos $34: 147-158$

Niemimaa J (1995) Activity patterns and home ranges of the American mink Mustela vison in the Finnish outer archipelago. Ann Zool Fenn 32:117-121

Powell RA (1979) Ecological energetics and foraging strategies of the fisher Martes pennanti. J Anim Ecol 48:195-212

Powell RA (1994) Structure and spacing of Martes population. In: Buskirk SW, Harested AS, Raphael MG, Powell RA (eds) Martens, sables and fishers, biology and conservation. Cornell University Press, London, pp 101-121

Robitaille JF, Baron G (1987) Seasonal changes in the activity budget of captive Ermine, Mustela erminea L. Can J Zool 65(12):2864-2871

Rooney SM, Wolfe A, Hayden TJ (1998) Autocorrelated data in telemetry studies: time to independence and the problem of behavioural effects. Mamm Rev 28(2):89-98
Skirnisson K (1986) Untersuchungen zum Raum-Zeit-System freilebender Steinmarder (Martes foina Erxleben, 1777). Beiträge zur Wildbiologie, $M+K$ Hansa Verlag, Hamburg, Germany

Thom MD, Harrington LA, Macdonald DW (2004) Why are American mink sexually dimorphic? A role for niche separation. Oikos 105:525-535

Wichmann T (2002) Fischerei. In: NABU Mecklenburg-Vorpommern (ed) Die Lewitz-Ein Lebensraum im Wandel der Zeit. Schwerin, pp 101-104

Wiig Ø (1982) Sexual dimorphism in the skull of the feral American mink (Mustela vison Schreber). Zool Scr 11(4):315-316

Yamaguchi N, Rushton S, Macdonald DW (2003) Habitat preferences of feral American mink in the Upper Thames. J Mammal 84 (4):1356-1373

Zabala J, Zuberogoitia I, Martinez-Climent JA (2007) Spacing pattern, intersexual competition and niche segregation in American mink. Ann Zool Fenn 44:249-258

Zalewski A (2001) Seasonal and sexual variation in diel activity rhythms of pine marten Martes martes in the Bialowieza National Park (Poland). Acta Theriol 46:295-304

Zielinski WJ (1988) The influence of daily variation in foraging cost on the activity of small carnivores. Anim Behav 36:239-249

Zimmermann H (2002) Natur- und Landschaftsschutz. In: NABU Mecklenburg-Vorpommern (ed) Die Lewitz-Ein Lebensraum im Wandel der Zeit. Schwerin, pp 21-32

Zschille J (2006) Der Mink. In: Neubürger auf dem Vormarsch. Sonderheft DLV, Berlin, pp 60-79

Zschille J, Stier N, Roth M (2008) Radio tagging American mink (Mustela vison) - experience with collar- and intraperitoneal implanted transmitters. Eur J Wildl Res 54:263-268

Zuberogoitia I, Zabala J, Martinez JA (2006) Diurnal activity and observations of the hunting and ranging behaviour of the American mink (Mustela vison). Mammalia 70:310-312 